\title{
The reasons for triple therapy in stable COPD patients in Japanese clinical practice
}

\author{
This article was published in the following Dove Press journal: \\ International Journal of COPD \\ 4 June 2015 \\ Number of times this article has been viewed
}

\author{
Masaki Miyazaki' \\ Hidetoshi Nakamura ${ }^{1,2}$ \\ Saeko Takahashi' \\ Shotaro Chubachi' \\ Mamoru Sasaki' \\ Mizuha Haraguchi' \\ Hideki Terai' \\ Makoto Ishii' \\ Koichi Fukunaga' \\ Sadatomo Tasaka' \\ Kenzo Soejima' \\ Koichiro Asano 3 \\ Tomoko Betsuyaku' \\ On behalf of the Keio \\ COPD Comorbidity \\ Research (K-CCR) group \\ 'Division of Pulmonary Medicine, \\ Department of Medicine, Keio \\ University School of Medicine, \\ Tokyo, ${ }^{2}$ Department of Respiratory \\ Medicine, Saitama Medical University, \\ Saitama, ${ }^{3}$ Division of Pulmonary \\ Medicine, Department of Medicine, \\ Tokai University School of Medicine, \\ Kanagawa, Japan
}

\begin{abstract}
Background: Triple combination therapy involving long-acting muscarinic antagonists long-acting $\beta_{2}$ agonists, and inhaled corticosteroids has recently become an option for maintenance treatment of COPD. Some add-on clinical trials have reported the benefits of these combinations. However, the process to step up to triple therapy varies for individual cases.

Methods: Keio University and affiliated hospitals conducted an observational COPD cohort study, recruiting patients diagnosed as having COPD by pulmonary physicians and those referred for investigation of possible COPD. Their prescription history and clinical course were retrospectively analyzed based on the physicians' medical records and patient questionnaires. This study was registered with UMIN (UMIN000003470, April 10, 2010).

Results: A total of 95 of the 445 COPD patients (21\%) were treated with inhaled corticosteroids/ long-acting $\beta_{2}$ agonists/long-acting muscarinic antagonists as maintenance therapy, including 12 in COPD Grade I, 31 in Grade II, 38 in Grade III, and 14 in Grade IV, based on the Global Initiative for Chronic Obstructive Lung Disease spirometric grading. For more than half of the patients on triple therapy, the treatment had been intensified due to unsatisfactory improvement of symptoms, and $32 \%$ were treated with triple therapy due to comorbid asthma. In contrast, there were COPD patients whose therapy was maintained after starting with triple therapy because of their serious conditions or concurrent exacerbation at diagnosis $(8 \%)$.

Conclusion: Triple therapy was often prescribed in the real-life management of COPD, even in patients whose airflow limitation was not severe. To better control symptoms was the major reason for choosing triple therapy, regardless of the severity of COPD, in Japan.
\end{abstract}

Keywords: chronic obstructive pulmonary disease, inhaled corticosteroids, long-acting muscarinic antagonists, long-acting $\beta_{2}$ agonists, triple therapy

\section{Introduction}

COPD is a prominent cause of disability and death worldwide, and the goals of pharmacologic therapy for COPD are to control symptoms, improve health status, and reduce the frequency of exacerbations, as suggested by the Global initiative for chronic Obstructive Lung Disease (GOLD), updated 2011. ${ }^{1}$ Most diagnosed patients are started on monotherapy involving bronchodilators such as long-acting muscarinic antagonists (LAMAs) or long-acting $\beta_{2}$ agonists (LABAs). Current guidelines provide recommendations concerning stepwise intensification of therapy with combined use of long-acting bronchodilators and inhaled corticosteroids (ICS) to optimize outcomes in patients with inadequate control on monotherapy, but do not address "stepping down" therapy in COPD. ${ }^{1}$ It has been demonstrated that, in some patients, triple therapy, which adds an anticholinergic to an ICS and LABA, has been associated with greater improvements in lung function and quality of life and reduced rates of hospitalization
Correspondence: Hidetoshi Nakamura Department of Respiratory Medicine, Saitama Medical University, 38 Morohongo Moroyama-machi, Iruma-gun, Saitama 350-0495, Japan

$\mathrm{Tel} / \mathrm{fax}+8 \mid 492761319$

Email hnakamur@saitama-med.ac.jp 
compared with anticholinergic therapy alone..$^{2-6}$ Chatterjee et al reported a retrospective observational study showing that triple therapy with a fluticasone-salmeterol combination added to tiotropium compared with tiotropium monotherapy was associated with significant reductions in the adjusted risks of moderate exacerbation and any exacerbation over a follow-up period of up to 1 year. ${ }^{7}$ According to a recent systematic review including 20 trials (6,803 participants), triple therapy seemed to be the most promising for patients with moderate to very severe COPD. ${ }^{8}$ While the efficacy and tolerability of triple therapy have been evaluated in many clinical trials, it is important to know the process of getting to triple therapy and the reasons why pulmonary physicians choose triple therapy for individual patients in real-world clinical practice. ${ }^{9}$ Therefore, the proportion of patients on triple therapy was analyzed, and the reasons for combining three drugs were retrospectively investigated in a well-characterized cohort study in Japan.

\section{Methods}

\section{Study population}

This was part of a prospective observational study investigating the management of COPD, the Keio COPD Comorbidity Research (K-CCR). ${ }^{10,11}$ A total of 572 subjects were recruited at Keio University Hospital and its affiliated hospitals between April 2010 and December 2012, including patients who had been diagnosed as having COPD by pulmonary physicians and patients referred for investigation of possible COPD based on their symptoms and/or presence of emphysematous changes on computed tomography (CT). Patients with a history of lung resection surgery or other serious, uncontrolled diseases likely to interfere with the study were excluded. For the purpose of this study, only patients with spirometrically confirmed COPD $(n=445)$ were analyzed. All patients were clinically stable and without exacerbations for at least 1 month prior to the study. All questionnaires were completed at home in the stable state. At enrollment and 1 year later, a full medical and smoking history and information about current pharmacological treatment were obtained. The protocol was approved by the ethics committee of Keio University School of Medicine on July 29, 2009 (No 20090008) and its affiliated hospitals listed in the acknowledgments section, and written informed consent was obtained from each patient.

\section{Assessment of health-related quality of life}

Patients were asked to complete COPD Assessment Test (CAT) questionnaires at home in the stable state. The CAT questionnaire had eight items, covering cough, phlegm, chest tightness, breathlessness, activity limitation, confidence, sleep, and energy. ${ }^{12}$ It has been successfully translated into Japanese, and its validity was evaluated in our previous study. ${ }^{10}$

\section{Evaluation of emphysema on CT scan}

Quantitative CT analyses of emphysema were performed in 291 patients with COPD, as previously reported. ${ }^{11}$ Briefly, low-attenuation areas (LAAs) were determined using a threshold level of $-950 \mathrm{HU}$ on a Discovery CT 750HD CT system (GE Healthcare, Tokyo, Japan), or the threshold on each model of CT scanner was adjusted using a CT scanner test object, and its percentage relative to the entire lung area (LAA\%) was calculated using the workstation Lexus $64^{\circledR}$ (AZE Ltd., Tokyo, Japan).

\section{Statistical analysis}

Data are presented as mean \pm standard deviation (SD). The frequencies were compared among four groups of airflow obstruction by Kruskal-Wallis and Mann-Whitney $U$-tests with the Bonferroni correction. In these multiple comparisons, $P<0.0083$ was considered significant. Analysis of variance and the Tukey-Kramer HSD (honestly significant difference) test were performed to compare mean values of the number of drugs among the four groups. The JonckheereTerpstra test was used to examine trends for the four groups of subjects according to the therapy and the extent of emphysema. $P$-values less than 0.05 were considered significant in these analyses. All data were analyzed using JMP version 9.0.2 for Windows.

\section{Results}

\section{Characteristics of the patient population}

A total of 445 eligible patients (COPD Grade I-IV: 93, 205, 114 , and 33, respectively) were the subjects for this analysis. Table 1 shows the characteristics of the patient population according to the GOLD spirometric grading. Of the 445 patients, 95 were treated with ICS/LABA/LAMA as maintenance therapy at the time of study entry. The proportions of patients on the various treatment options are listed in Table 2.

\section{Proportion of patients on triple therapy}

Table 3 shows the numbers of patients on no therapy, single therapy, double therapy, and triple therapy by each GOLD spirometric grade of COPD patients. Even in patients without severe airflow limitation, 13\% in Grade I and 15\% in Grade II were on triple therapy, although the proportion of 
Table I Characteristics of the study populations

\begin{tabular}{|c|c|c|c|c|c|}
\hline & Grade I & Grade II & Grade III & Grade IV & $P$-value \\
\hline Number (\%) & $93(2 \mathrm{I})$ & $205(46)$ & II 4 (26) & $33(7)$ & \\
\hline Female (\%) & II (I2) & $20(10)$ & $5(4)$ & $2(6)$ & \\
\hline Age, years & $71.6 \pm 8.1$ & $72.8 \pm 8.4$ & $72.8 \pm 7.7$ & $72.3 \pm 7.9$ & ns \\
\hline Smoking index, pack-years & $53.0 \pm 31.5$ & $53.7 \pm 27.6^{*}$ & $63.9 \pm 31.2$ & $54.0 \pm 28.0$ & 0.02 \\
\hline Current smokers (\%) & $9(10)$ & $30(15)$ & $15(13)$ & $4(13)$ & ns \\
\hline $\mathrm{BMI}, \mathrm{kg} / \mathrm{m}^{2}$ & $22.9 \pm 2.9 *, \#$ & $22.9 \pm 3.2^{*, \#}$ & $21.7 \pm 3.5^{\#}$ & $19.9 \pm 2.9$ & $<0.000$ I \\
\hline $\mathrm{FEV}_{1} / \mathrm{FVC}(\%)$ & $63.3 \pm 4.9$ & $55.4 \pm 8.2$ & $4 I .1 \pm 9.3$ & $32.8 \pm 8.1$ & $<0.000$ I \\
\hline $\mathrm{FEV}_{1}, \mathrm{~mL}$ & $2,379 \pm 453$ & $\mathrm{I}, 720 \pm 400$ & $\mathrm{I}, 069 \pm 224$ & $633 \pm 120$ & $<0.000$ I \\
\hline$\% F E V_{1}$ & $91.2 \pm 9.7$ & $65.3 \pm 8$ & $40.4 \pm 6$ & $24.2 \pm 3.2$ & $<0.000$ I \\
\hline
\end{tabular}

Notes: Data are presented as mean \pm standard deviation. $* P<0.05$ vs Grade III, $\# P<0.05$ vs Grade IV.

Abbreviations: $\mathrm{BMI}$, body mass index; $\mathrm{FEV}_{1}$, forced expiratory volume in I second; FVC, forced vital capacity; ns, not significant.

patients on triple therapy became higher as the grades became higher $(P<0.01)$. A total of 95 COPD patients were on triple therapy, of which only seven (7\%) started their COPD treatment with triple therapy, and the others had been treated with LABA/LAMA (27\%), LAMA (27\%), ICS/LABA (21\%), or ICS/LAMA $(10 \%)$ prior to the step up to triple therapy. One year after enrollment, triple therapy was continued for $76(80 \%)$ of the patients. On the other hand, reasons for step down to LABA/LAMA for four (4\%), LAMA one (1\%), ICS/LABA five $(5 \%)$, LABA two $(2 \%)$, or none for two $(2 \%)$ varied, including adverse effects of ICS in four patients (cough, hoarseness, nausea, and respiratory infection) and of LAMA in four patients (difficulty with urination).

\section{Reasons for step up to triple therapy}

The information concerning the reasons for triple therapy was obtained by reviewing medical records. The reasons were classified into six groups: 1) added due to unsatisfactory improvement in shortness of breath with single or double therapy; 2) added due to unsatisfactory improvement in cough/sputum with single or double therapy; 3 ) addition of LAMA because of newly diagnosed COPD during the course of asthma treatment; 4) addition of ICS/LABA due to likely comorbid asthma

Table 2 Breakdown of drugs in single, double, or triple therapy

\begin{tabular}{lll}
\hline $\begin{array}{l}\text { Number } \\
\text { of drugs }\end{array}$ & $\begin{array}{l}\text { Breakdown } \\
\text { of drugs }\end{array}$ & $\begin{array}{l}\text { Number of } \\
\text { patients (\%) }\end{array}$ \\
\hline None & & $114(26)$ \\
Single & ICS & $5(1)$ \\
& LABA & $19(4)$ \\
& LAMA & $123(28)$ \\
Double & ICS/LABA & $46(10)$ \\
& LABA/LAMA & $39(9)$ \\
& ICS/LAMA & $4(1)$ \\
Triple & ICS/LABA/LAMA & $95(21)$ \\
\hline
\end{tabular}

Abbreviations: ICS, inhaled corticosteroids; LABA, long-acting $\beta_{2}$ agonist; LAMA, long-acting muscarinic antagonist. during the course of COPD treatment with LAMA; 5) sustained use after starting with triple therapy because of severe symptoms and/or exacerbation on diagnosis; and 6) others. As shown in Figure 1, the reasons for starting triple therapy varied. For more than half of the patients, the treatment had been added because of unsatisfactory improvement of symptoms, including shortness of breath and cough/sputum, regardless of the levels of airflow limitation. Comorbid asthma was one of the non-negligible reasons for triple therapy. Among the patients on triple therapy, in $17 \%$ of COPD Grade I, $10 \%$ of Grade II, $21 \%$ of Grade III, and 14\% of Grade IV patients, LAMA was subsequently added based on newly diagnosed COPD following asthma treated with ICS/LABA. On the other hand, for $17 \%$ of COPD Grade I, $13 \%$ of Grade II, $18 \%$ of Grade III, and $14 \%$ of Grade IV patients, ICS/LABA was added because the clinical feature of comorbid asthma was later recognized during the course of COPD treatment with LAMA. In contrast to these stepwise increases, there were patients whose initial treatment was triple therapy because of their serious conditions or concurrent exacerbation on diagnosis of COPD $(0 \%$ of COPD Grade I, $3 \%$ of Grade II, $16 \%$ of Grade III, and $7 \%$ of Grade IV).

\section{Relationships of the CAT score and the number of drugs}

The above findings suggested that a major reason for triple therapy in clinical practice was unsatisfactory improvement

Table 3 Number of patients on none, single, double, or triple therapy in the groups based on GOLD spirometric grading

\begin{tabular}{lllll}
\hline & Grade I & Grade II & Grade III & Grade IV \\
\hline None (\%) & $38(4 \mathrm{I})$ & $5 \mathrm{I}(25)$ & $\mathrm{I} 0(9)$ & $4(\mathrm{II})$ \\
Single (\%) & $36(39)$ & $77(38)$ & $33(29)$ & $\mathrm{I}(3)$ \\
Double (\%) & $7(7)$ & $46(22)$ & $33(29)$ & $\mathrm{I})(43)$ \\
Triple (\%) & I2(I3) & $3 \mathrm{I}(15)$ & $38(33)$ & $\mathrm{I} 4(43)$ \\
\hline
\end{tabular}

Abbreviation: GOLD, Global initiative for chronic Obstructive Lung Disease. 


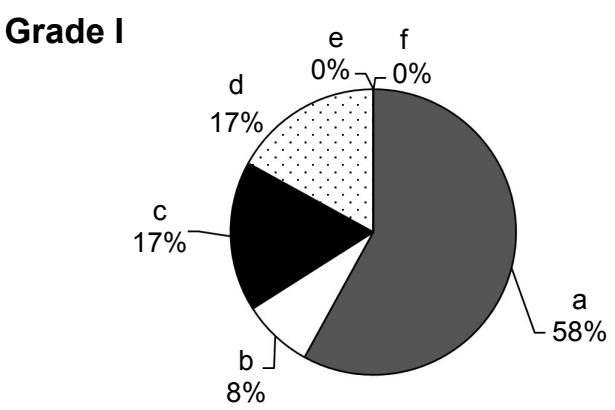

Grade II
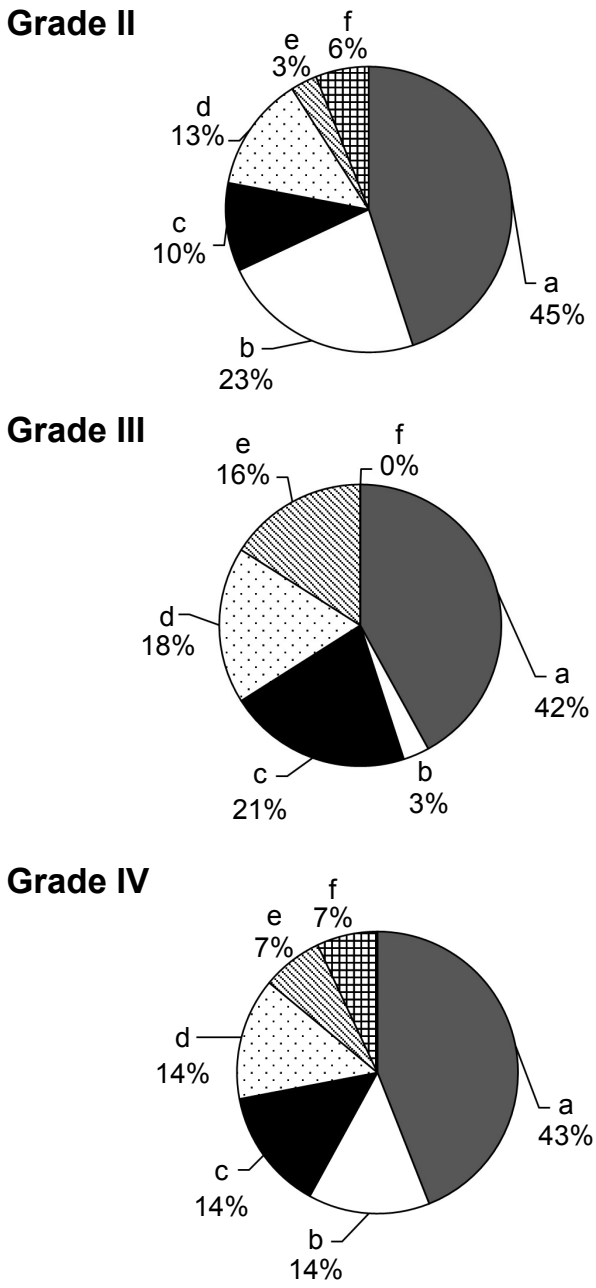

Figure I Reasons for triple therapy in GOLD Grade I, Grade II, Grade III, and Grade IV.

Notes: a) Added due to unsatisfactory improvement in shortness of breath with single or double therapy; b) added due to unsatisfactory improvement in cough/ sputum with single or double therapy; c) addition of LAMA because of newly diagnosed COPD during the course of asthma treatment; d) addition of ICS/LABA due to likely comorbid asthma during the course of COPD treatment with LAMA; e) sustained use after starting with triple therapy because of severe symptoms and/ or exacerbation on diagnosis; and $f$ ) others.

Abbreviations: GOLD, Global initiative for chronic Obstructive Lung Disease; LAMA, long-acting muscarinic antagonist; COPD, chronic obstructive pulmonary disease; ICS, inhaled corticosteroids; LABA, long-acting $\beta_{2}$ agonist.

of symptoms. Therefore, whether COPD-related quality of life was related to the number of drugs used (ie, none, single, double, or triple) was evaluated. In patients with moderate airflow limitation (GOLD Grade II), the CAT score increased significantly as the number of drugs increased (Figure 2).

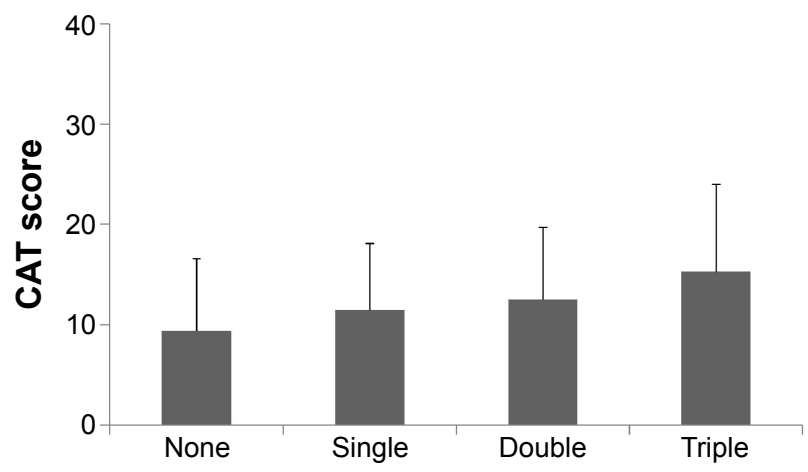

Figure 2 Comparison of CAT scores in GOLD Grade II patients according to the number of inhaled medications.

Notes: Data are presented as mean \pm standard deviation. The CAT score increases significantly as the number of drugs increases $(P<0.05)$.

Abbreviations: CAT, COPD Assessment Test; GOLD, Global initiative for chronic Obstructive Lung Disease.

The CAT score did not differ by the number of drugs in the other GOLD grades (data not shown). The CAT score was obtained from 89 (96\% in Grade I), 197 (96\% in Grade II), 104 (91\% in Grade III), and 27 patients (82\% in Grade IV).

\section{The frequency of triple therapy according to the 20 I I GOLD classification}

Because the frequency of COPD exacerbations was not recorded prior to enrollment in the present study, future risk was assessed only by the GOLD spirometric classification. Based on the extent of airflow limitation and CAT scores, there were 129 (31\%), 157 (38\%), 41 (10\%), and 90 (22\%) patients in GOLD A ( $\%$ forced expiratory volume in 1 second $\left[\% \mathrm{FEV}_{1}\right] \geq 50 \%$ and $\left.\mathrm{CAT}<10\right)$, GOLD B $\left(\% \mathrm{FEV}_{1} \geq 50 \%\right.$ and $\mathrm{CAT} \geq 10)$, GOLD C $\left(\% \mathrm{FEV}_{1}<50 \%\right.$ and CAT $<10)$, and GOLD D $\left(\% \mathrm{FEV}_{1}<50 \%\right.$ and CAT $\left.\geq 10\right)$ groups, respectively. The frequency of triple therapy was higher in the GOLD D group than in the GOLD A group (37\% vs 9\%) (Figure 3).

\section{The frequency of triple therapy according to the severity of emphysema}

Quantitative analysis of emphysema on CT was performed for 291 COPD patients, and they were classified into no $(\mathrm{LAA} \%<10, \mathrm{n}=121,42 \%)$, mild $(10 \leq \mathrm{LAA} \%<20, \mathrm{n}=70$, $24 \%)$, moderate $(20 \leq \mathrm{LAA} \%<30, \mathrm{n}=52,18 \%)$, and severe emphysema ( $\mathrm{LAA} \% \geq 30, \mathrm{n}=48,16 \%$ ). The frequency of triple therapy was higher according to the severity of emphysema (Figure 4, $P<0.01$ ).

\section{Discussion}

The present retrospective analysis showed that 95 of 445 COPD patients (21\%) were treated with ICS/LABA/LAMA as maintenance therapy in the K-CCR cohort at the time 


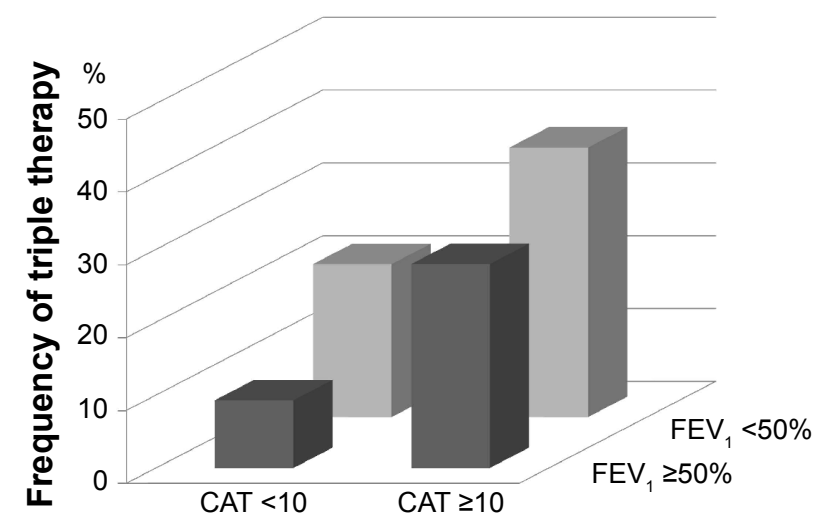

Figure 3 Comparison of the frequency of triple therapy using the GOLD 201 I classification.

Notes: The frequency is $9 \%$ in GOLD A (\%FEV $\geq 50 \%$ and CAT $<10$ ), $28 \%$ in GOLD B (\%FEV $\geq 50 \%$ and CAT $\geq 10), 21 \%$ in GOLD C $(\% \mathrm{FEV},<50 \%$ and CAT $<10)$, and $37 \%$ in GOLD D $\left(\% F E V_{1}<50 \%\right.$ and CAT $\left.\geq 10\right)$. The frequency is higher in GOLD D than in GOLD A $(P<0.001)$.

Abbreviations: GOLD, Global initiative for chronic Obstructive Lung Disease; $\mathrm{FEV}_{1}$, forced expiratory volume in I second; CAT, COPD Assessment Test.

of enrollment. The track record for inhaled medications in those patients had been variable, but the treatment had been intensified during the course of disease due to unsatisfactory improvement of their symptoms on preceding therapy for more than half of the patients who were on triple therapy. In other words, COPD symptom-based management was routinely performed in real-world clinical practice in Japan.

In this study, CAT scores increased significantly as the number of drugs increased within the same degree of airflow limitation (GOLD Grade II). The frequency of triple therapy was the highest in the GOLD D group (37\%), for which triple therapy was included among the first choice options in the GOLD guideline, but there were a number of patients on

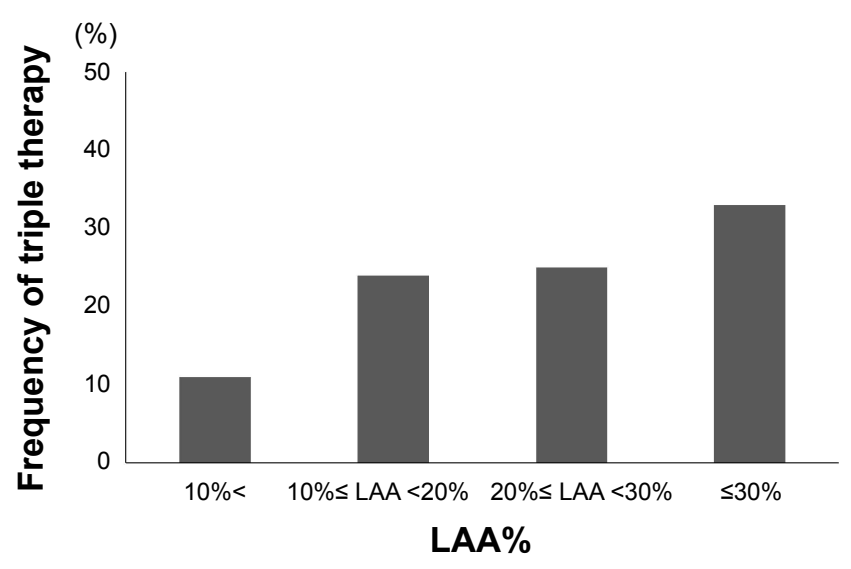

Figure 4 Comparison of the frequency of triple therapy among the groups divided by $L A A \%$ on quantitative $C T$ analysis.

Notes: No emphysema (LAA\% $<10, n=121$ ), mild emphysema $(10 \leq \mathrm{LAA} \%<20$, $n=70)$, moderate emphysema $(20 \leq L A A \%<30, n=52)$, and severe emphysema $(\mathrm{LAA} \% \geq 30, n=48)$. The frequency becomes significantly higher as the severity of emphysema increases $(P<0.01)$.

Abbreviations: LAA, low-attenuation area; CT, computed tomography. triple therapy even in the GOLD A (9\%), B (28\%), and C (21\%) groups. Wurst et al recently reported that a percentage of COPD patients (23\%) similar to the present study (21\%) were treated with triple therapy at the time of diagnosis of COPD in primary care settings in the United Kingdom. ${ }^{13}$ They also stated that $46 \%$ of patients treated with LABA or LAMA progressed to triple therapy within 2 years after the diagnosis, while more than half of the patients who started with triple therapy stepped down to ICS/LABA (25\%) and LAMA (31\%). In the present study, $80 \%$ of patients on triple therapy at enrollment remained on triple therapy 1 year later in clinical practice in Japan. Price et al also reported that $24 \%$ of COPD patients were on triple therapy in the United Kingdom primary care setting. ${ }^{14}$ They demonstrated that patients on triple therapy had relatively higher frequencies of exacerbations and CAT scores than those on single or double therapy based on electronic patient records and patient-completed questionnaires. Koblizek et al reported that despite the high awareness of the GOLD 2011 strategy among Czech COPD specialists, its real-life implementation was rather insufficient. ${ }^{15}$ They claimed that $15.5 \%$ of COPD patients received ICS unnecessarily, and in $12.2 \%$ of cases, ICS was omitted contrary to the guideline recommendations. Among the COPD subjects enrolled in the COPDGene Study, subjects who were on triple therapy had the highest frequencies of exacerbations and severe exacerbations compared to others. ${ }^{16}$ The present study found that the frequency of triple therapy increased with increasing severity of emphysema, which was consistent with the results of the COPDGene Study. ${ }^{16}$ Taken together, the number of medications may identify a more severe phenotype of COPD that is highly susceptible to exacerbations and/or is highly symptomatic. On the other hand, it has also been reported that, in patients with severe COPD receiving tiotropium plus salmeterol, the risk of moderate or severe exacerbations was similar among those who discontinued inhaled glucocorticoids and those who continued glucocorticoid therapy, suggesting that the withdrawal of glucocorticoids from triple therapy does not result in an increased risk of exacerbation. ${ }^{17}$

It should be noted that in the present study, another major reason for triple therapy was the presence of comorbid asthma. Although the differential diagnosis between asthma and COPD has been sufficiently stressed, the distinction between chronic asthma and COPD might not always be clear in some patients, even for pulmonary physicians. A recent New Zealand study reported that asthma was the predominant COPD phenotype.$^{18}$ However, COPD patients with an asthmatic phenotype and fixed airway obstruction have a pulmonary function pattern that differs from that of 
classic COPD patients. ${ }^{19}$ Nishimura et al suggested that only $14 \%$ of COPD patients were treated with ICS in Japan when asthma was clinically excluded. ${ }^{20}$ Percentages of patients on ICS therapy were $34 \%, 69 \%, 60 \%$, and $50 \%$ in the present, Wurst's, ${ }^{13}$ Price's, ${ }^{14}$ and Koblizek's ${ }^{15}$ studies, respectively. Frequencies of concomitant asthma were 20\%, 44\%, 28\%, and $0 \%$, respectively, in the four studies, ie, patients with asthma were excluded in Koblizek's study. These results may imply that more COPD patients are treated with ICS in the United Kingdom and the Czech Republic than in Japan, regardless of the presence or absence of comorbid asthma. These differences may be attributed to different phenotypes of COPD, including asthma COPD overlap syndrome, ${ }^{21}$ frequency of exacerbations, ${ }^{22}$ and response to ICS, in different ethnic groups. In addition, adverse effects of ICS should also be considered. Four patients on triple therapy failed to continue ICS due to cough, hoarseness, nausea, and respiratory infection in the present study. Pneumonia, diabetes, osteoporosis, and cataract are known to be increased by ICS as well. ${ }^{23}$

The results of the present study must be interpreted within the context of its potential limitations. The first is that the population of this study was not the result of an epidemiological design, but only represented patients who were routinely followed by or referred to the University hospital or its affiliated hospitals in the Tokyo area and agreed to voluntarily participate in the study. Nevertheless, the population was quite large (445 COPD patients) and very similar in its characteristics to COPD patients reported in other cohort studies conducted in other areas of Japan. ${ }^{24,25}$ We also consider the present data reliable since they were collected both from the records of pulmonary physicians and from information provided by the patients. The second limitation was the fact that whether the patients were actually taking the prescribed medications was not ascertained. Considering the old age of the study population, the monitoring of usage should be taken into account. Third, as previously mentioned, data were collected retrospectively, and it was not feasible to objectively evaluate the benefit of triple therapy in clinical settings. There should have also been some reasons for pulmonary physicians not to choose triple therapy, such as the anticipated adverse effects or burden of cost for the patients. A new prospective study is needed to help physicians guide not only the prescription, but also the withdrawal of triple therapy in controlling symptoms for stable COPD patients. This observational study has thereafter motivated us to conduct a prospective study to understand how effective triple therapy is in controlling symptoms when compared with other treatment strategies in stable COPD patients in Japan. ${ }^{26}$

\section{Conclusion}

Better control of symptoms (in more than half of the cases), and the presence of comorbid asthma (in about one-third of the cases) were the major reasons for choosing triple therapy regardless of the severity of airflow limitation in clinical practice in Japan.

\section{Acknowledgments}

The authors would like to acknowledge Chiyomi Uemura for her contribution to collecting data and all the members of the K-CCR group for participation in this study, including Saiseikai Utsunomiya Hospital, Eiju General Hospital, Tokyo Saiseikai Central Hospital, Sano Public Welfare General Hospital, Nihon Kokan Hospital, Saitama Social Insurance Hospital, Kawasaki City Ida Hospital, Saitama City Hospital, Tokyo Medical Center, Tokyo Dental College Ichikawa General Hospital, Tokyo Electric Power Company Hospital, and International Medical Welfare College Shioya Hospital. This study was funded by GlaxoSmithKline.

\section{Author contributions}

Study idea and design were contributed by MM, HN, KA, and TB. Statistical analysis was performed by MM. Data acquisition was done by MM, STak, SC, MS, MH, HT, $\mathrm{MI}, \mathrm{KF}, \mathrm{STas}, \mathrm{KS}$, and TB. Interpretation of results was conducted by MM, HN, STak, MI, KF, STas, KS, and TB. Manuscript drafting/revision was done by MM, HN, and TB. All of the authors have read the manuscript and agree with the content contained within. All authors contributed toward data analysis, drafting, and critically revising the paper and agree to be accountable for all aspects of the work.

\section{Disclosure}

TB discloses having received honoraria/paid expert testimony and her university having received research grants from GlaxoSmithKline. The other authors have no conflicts to declare.

\section{References}

1. Global Initiative for Chronic Obstructive Lung Disease. Global strategy for diagnosis, management, and prevention of COPD. Available from: http://www.goldcopd.org/guidelines-global-strategy-for-diagnosismanagement.html. Accessed December 6, 2014.

2. Fukahori S, Matsuse H, Takamura N, et al. Prevalence of chronic obstructive pulmonary diseases in general clinics in terms of $\mathrm{FEV}_{1} / \mathrm{FVC}$. Int $J$ Clin Pract. 2009;63(2):269-274. 
3. Aaron SD, Vandemheen KL, Fergusson D, et al. Canadian Thoracic Society/Canadian Respiratory Clinical Research Consortium. Tiotropium in combination with placebo, salmeterol, or fluticasone-salmeterol for treatment of chronic obstructive pulmonary disease: a randomized trial. Ann Intern Med. 2007;146(8):545-555.

4. Perng DW, Wu CC, Su KC, Lee YC, Perng RP, Tao CW. Additive benefits of tiotropium in COPD patients treated with long-acting beta agonists and corticosteroids. Respirology. 2006;11(5):598-602.

5. Singh D, Brooks J, Hagan G, Cahn A, O'Connor BJ. Superiority of triple therapy with salmeterol/fluticasone propionate and tiotropium bromide versus individual components in moderate to severe COPD. Thorax. 2008;63(7):592-598.

6. Welte T, Miravitlles M, Hernandez P, et al. Efficacy and tolerability of budesonide/formoterol added to tiotropium in patients with chronic obstructive pulmonary disease. Am J Respir Crit Care Med. 2009;180(8):741-750.

7. Chatterjee A, Shah M, D’Souza AO, Bechtel B, Crater G, Dalal AA. Observational study on the impact of initiating tiotropium alone versus tiotropium with fluticasone propionate/salmeterol combination therapy on outcomes and costs in chronic obstructive pulmonary disease. Respir Res. 2012;13:15.

8. Rodrigo GJ, Plaza V, Castro-Rodríguez JA. Comparison of three combined pharmacological approaches with tiotropium monotherapy in stable moderate to severe COPD: a systematic review. Pulm Pharmacol Ther. 2012;25(1):40-47.

9. Cazzola M, Matera MG. Triple combinations in chronic obstructive pulmonary disease - is three better than two? Expert Opin Pharmacother. 2014;15(17):2475-2478.

10. Miyazaki M, Nakamura H, Chubachi S, et al. Analysis of comorbid factors that increase the COPD assessment test scores. Respir Res. 2014;15:13.

11. Chubachi S, Nakamura H, Sasaki M, et al. Polymorphism of low-density lipoprotein receptor-related protein 5 gene and emphysema severity are associated with osteoporosis in Japanese patients with or at risk for COPD. Respirology. Epub 2014 Nov 12.

12. Jones PW, Harding G, Berry P, Wiklund I, Chen WH, Leidy N. Development and first validation of the COPD Assessment Test. Eur Respir J. 2009;34(3):648-654.

13. Wurst KE, Punekar YS, Shukla A. Treatment evolution after COPD diagnosis in the UK primary care setting. PLoS One. 2014;9(9):e105296.
14. Price D, West D, Brusselle G, et al. Management of COPD in the UK primary-care setting: an analysis of real-life prescribing patterns. Int $J$ Chron Obstruct Pulmon Dis. 2014;9:889-905.

15. Koblizek V, Pecen L, Zatloukal J, et al. Real-life GOLD 2011 implementation: the management of COPD lacks correct classification and adequate treatment. PLoS One. 2014;9(11):e111078.

16. Park SJ, Make B, Hersh CP, Bowler RP. Significance of medication history at the time of entry into the COPDGene study: relationship with exacerbation and CT metrics. COPD. Epub 2014 Sep 25.

17. Magnussen H, Disse B, Rodriguez-Roisin R, et al. Withdrawal of inhaled glucocorticoids and exacerbations of COPD. $N$ Engl J Med. 2014;371(14):1285-1294

18. Marsh SE, Travers J, Weatherall M, et al. Proportional classifications of COPD phenotypes. Thorax. 2008;63(9):761-767.

19. Fabbri LM, Romagnoli M, Corbetta L, et al. Differences in airway inflammation in patients with fixed airflow obstruction due to asthma or chronic obstructive pulmonary disease. Am J Respir Crit Care Med. $2003 ; 167(3): 418-424$.

20. Nishimura M, Makita $H$, Nagai K, et al. Annual change in pulmonary function and clinical phenotype in chronic obstructive pulmonary disease. Am J Respir Crit Care Med. 2012;185(1):44-52.

21. Kim SR, Rhee YK. Overlap between asthma and COPD: where the two diseases converge. Allergy Asthma Immunol Res. 2010;2(4):209-214.

22. Suzuki M, Makita H, Ito YM, et al. Clinical features and determinants of COPD exacerbation in the Hokkaido COPD cohort study. Eur Respir J. 2014;43(5):1289-1297.

23. Flynn RW, MacDonald TM, Hapca A, MacKenzie IS, Schembri S Quantifying the real life risk profile of inhaled corticosteroids in COPD by record linkage analysis. Respir Res. 2014;15:141.

24. Makita H, Nasuhara Y, Nagai K, et al. Characterisation of phenotypes based on severity of emphysema in chronic obstructive pulmonary disease. Thorax. 2007;62(11):932-937.

25. Tanabe N, Muro S, Hirai T, et al. Impact of exacerbations on emphysema progression in chronic obstructive pulmonary disease. Am J Respir Crit Care Med. 2011;183(12):1653-1659.

26. Betsuyaku T, Kato M, Fujimoto K, et al. A study to assess COPD symptombased management and to optimise treatment strategy in Japan (COSMOS-J) based on GOLD 2011. Int J Chron Obstruct Pulmon Dis. 2013;8:453-459.
International Journal of COPD

\section{Publish your work in this journal}

The International Journal of COPD is an international, peer-reviewed journal of therapeutics and pharmacology focusing on concise rapid reporting of clinical studies and reviews in COPD. Special focus is given to the pathophysiological processes underlying the disease, intervention programs, patient focused education, and self management protocols.

\section{Dovepress}

This journal is indexed on PubMed Central, MedLine and CAS. The manuscript management system is completely online and includes a very quick and fair peer-review system, which is all easy to use. Visit http://www.dovepress.com/testimonials.php to read real quotes from published authors. 